\title{
Preoperative Albumin-Bilirubin Grade as a Useful Prognostic Indicator in Patients With Pancreatic Cancer
}

\author{
TAKUKI YAGYU, HIROAKI SAITO, TERUHISA SAKAMOTO, EI UCHINAKA, \\ MASAKI MORIMOTO, MASATAKA AMISAKI, JOJI WATANABE, NARUO TOKUYASU, \\ SOICHIRO HONJO, KEIGO ASHIDA and YOSHIYUKI FUJIWARA \\ Division of Surgical Oncology, Department of Surgery, School of Medicine, \\ Tottori University Faculty of Medicine, Yonago, Japan
}

\begin{abstract}
Background: The albumin-bilirubin (ALBI) grade assesses the severity of liver dysfunction in patients with hepatocellular carcinoma. Herein we investigated the prognostic significance of the combination of the ALBI grade with serum carbohydrate antigen 19-9 (CA 19-9) concentration, the most frequently used tumor marker in pancreatic cancer $(P C)$ in resected patients with $P C$. Materials and Methods: Included patients $(n=100)$ had a histopathological diagnosis of pancreatic cancer and underwent pancreatectomy. Serum concentrations of albumin, bilirubin, and CA19-9 were measured within 5 days before surgery. Patients were divided into groups with high and low CA19-9 (cut-off $\geq 35 \mathrm{U} / \mathrm{ml}$ ) and ALBI grade (2 and 3 vs. 1). Results: The 5-year overall survival (OS) rates of the $A L B I^{H i g h}$ and $A L B I^{L O w}$ groups were $21.6 \%$ and $35.3 \%$, respectively $(p=0.015)$. The 5-year OS rates of the CA19-9 ${ }^{\text {High }}$ and CA19-9 ${ }^{\text {Low }}$ groups were $22.2 \%$ and $41.5 \%$, respectively $(p=0.017)$. Patients were divided into groups $A$ ( $A L B I^{\text {High }}$ and CA19-9 $\left.{ }^{\text {High }}\right), B\left(A L B I^{\text {High }}\right.$ and CA19-9 ${ }^{\text {Low }}$ or $A L B I^{\text {Low }}$ and CA19-9 $\left.{ }^{\text {High }}\right)$, and $C$ (ALBI ${ }^{\text {Low }}$ and CA19$\left.9^{\text {Low }}\right)$. The 5-year $O S$ rates of groups $A, B$, and $C$ were $13.8 \%, 31.0 \%$, and $43.3 \%$, respectively $(p=0.0006)$. Multivariate analysis revealed that the ALBI grade combined with the CA19-9 concentration, served as an independent prognostic indicator. Conclusion: The combination of ALBI grade and CA19-9 concentration predicted the prognosis of patients with $P C$.
\end{abstract}

Correspondence to: Hiroaki Saito, Division of Surgical Oncology, Department of Surgery, School of Medicine, Tottori University Faculty of Medicine, 36-1 Nishi-cho, Yonago 683-8504, Japan. Tel: +81 859386567, Fax: +81859386569, e-mail: sai10@med.tottoriu.ac.jp

Key Words: Albumin, albumin-bilirubin grade, bilirubin, pancreatic cancer, prognosis.
Pancreatectomy with regional lymph node dissection is the mainstay curative treatment for pancreatic cancer (PC). However, the survival of patients with PC after macroscopically curative resection is short (5-year survival of 20.7-23.9\%, median survival of 22.3-23.6 months) even after adjuvant chemotherapy using gemcitabine (1-3). S-1 as adjuvant chemotherapy increases the 5-year overall survival (OS) rates of patients with stage I-III PC with no local residual or microscopic residual tumor after pancreatectomy with regional lymph node dissection to $44.1 \%$ (4). Thus, identifying and carefully monitoring patients with PC with a high possibility of recurrence after curative pancreatectomy is important for improving their prognoses. To this end, reliable prognostic indicators of PC are indispensable. For clinical applications, it is important to use indicators that are easy to measure using non-invasive techniques. In this regard, serum tumor markers are easy to measure and useful for diagnosis, prediction of survival rates, and monitoring recurrence. Carbohydrate antigen 19-9 (CA19-9) is a modified Lewis(a) blood group antigen and is currently recommended for clinical use by the National Comprehensive Cancer Network guidelines for PC. Several reports have described the usefulness of CA19-9 for diagnosis in symptomatic patients or for monitoring therapy and as a prognostic factor for PC $(5,6)$. However, approximately $20 \%$ of patients with PC have a normal serum CA19-9 level preoperatively (7). Therefore, a more sensitive marker is needed to improve the prognosis of patients with PC.

There is a growing interest in establishing novel noninvasive predictive biomarkers from hematological and serological variables for cancer. The albumin-bilirubin (ALBI) score was initially developed for assessing the severity of liver dysfunction in patients with hepatocellular carcinoma (HCC) (8). Moreover, the ALBI score is more useful for predicting the long-term survival of patients with HCC than the Child-Pugh score (9). Calculating the ALBI score requires measuring only serum bilirubin and albumin concentrations, which can be acquired from routine blood 
tests. Therefore, the ALBI score is an attractive candidate as a prognostic indicator of PC. Although most research on the ALBI score has focused on HCC, the ALBI score predicts the prognosis of patients with gastric cancer (10), indicating the possibility that ALBI may serve as a useful prognostic indicator of cancers other than HCC. To the best of our knowledge, there is no report showing the usefulness of the ALBI score for predicting the prognosis of patients with PC. Therefore, the aim of the current study was to determine the prognostic significance of the ALBI score, especially the combination of ALBI score with serum CA19-9 level, for PC.

\section{Materials and Methods}

Patients. This study was based on a retrospective analysis of 100 patients with pancreatic ductal adenocarcinoma who underwent pancreatectomy at our institution between July 2005 and December 2015. The clinicopathologicaI findings were determined according to the seventh edition of the Japanese Classification of Pancreatic Cancer (11). Patients underwent pancreaticoduodenectomy, distal pancreatectomy, or total pancreatectomy with regional lymph node dissection. Thirteen patients received neoadjuvant chemotherapy and 57 patients received adjuvant chemotherapy. The patients did not undergo neoadjuvant radiation therapy or chemoradiation therapy. Patients were periodically assessed for early recurrence using chest X-rays, ultrasonography, and computed tomography. Causes of death and patterns of recurrence were determined by reviewing medical records, including laboratory data, ultrasonography, computed tomography, scintigrams, peritoneal punctures, and laparotomies or by the direct inquiry of family members. Our present study was approved by the Institutional Review Board (approval number, 17A135), and the informed consent requirement was waived for this retrospective study.

Clinical parameters and ALBI grade. Preoperative blood tests, including serum concentrations of albumin, bilirubin, and CA19-9 were performed within 5 days before surgery. The ALBI score was calculated as follows: $\left[\left(\log _{10}\right.\right.$ bilirubin $\left.(\mu \mathrm{mol} / 1) \times 0.66\right]+[$ albumin $(\mathrm{g} / \mathrm{l}) \times-0.0852]$. The ALBI grade was assigned as follows: 1 : ALBI score $\leq-2.60,2:-2.60<$ ALBI score $\leq-1.39$ and 3 : ALBI score $>-1.39$, as proposed in previous studies $(9,12)$.

Statistical analysis. Differences in clinicopathological characteristics between the two groups defined according to ALBI grade were evaluated using the chi-squared test. Difference in the preoperative serum concentrations of bilirubin between patients with bile drainage and those without bile drainage was evaluated using the Mann-Whitney test. Correlations between serum albumin and bilirubin levels and between the ALBI scores and serum CA19-9 concentrations were analyzed using the Spearman rank correlation coefficient. Survival curves were calculated using the Kaplan-Meier method, and differences between the curves were evaluated using the log-rank test. Univariate and multivariate analyses of factors considered prognostic of OS were performed using Cox's proportional hazards model. Values of $p<0.05$ were considered significant. GraphPad Prism (GraphPad Software, Inc., La Jolla, CA, USA) and Stat View (Abacus Concepts, Inc., Berkeley, CA, USA) software were used for the statistical analyses.

\section{Results}

The mean serum albumin and bilirubin levels were 3.94 (range $=2.10$ to 4.90$) \mathrm{g} / \mathrm{dl}$ and 0.812 (range=0.20 to 6.20 ) $\mathrm{mg} / \mathrm{dl}$, respectively. Significant negative correlation was observed between serum albumin and bilirubin levels $(\mathrm{r}=-0.22, p=0.026)$. The mean ALBI score was -2.648 (range $=-3.625$ to -1.079 ). The numbers of patients with ALBI grades 1,2 , and 3 were 60,37 , and 3 , respectively. Only 3 patients were ALBI grade 3 . Therefore, patients were divided into ALBILow (ALBI grade 1) and ALBIHigh (ALBI grades 2 and 3 ) groups for further analysis.

The relationships between ALBI grade and the clinicopathological features are shown in Table I. Preoperative biliary drainage, such as percutaneous transhepatic biliary drainage, endoscopic retrograde biliary drainage and endoscopic nasobiliary drainage, was performed significantly more frequently in the ALBI ${ }^{\mathrm{High}}$ compared with the $\mathrm{ALBI}^{\mathrm{Low}}$ group ( $p=0.007)$. Preoperative bile drainage was administered to 32 patients because of obstruction of the bile duct. The preoperative serum concentrations of bilirubin were 1.2 \pm 1.1 $\mathrm{mg} / \mathrm{dl}$ and $0.63 \pm 0.27 \mathrm{mg} / \mathrm{dl}$ in patients with and without bile drainage, respectively $(p<0.0001)$.

The 5-year OS rates of patients in the $\mathrm{ALBI}^{\mathrm{High}}$ and $\mathrm{ALBI}^{\mathrm{L} o w}$ groups were $21.6 \%$ and $35.3 \%$, respectively $(p=0.015)$ (Figure 1). We then determined the prognostic significance of CA19-9 by dividing them into groups with high and low CA19-9 (cut-off $\geq 35 \mathrm{U} / \mathrm{ml}$ ). The 5-year OS rates of patients of the CA19-9 $9^{\text {High }}$ and CA19-9 ${ }^{\text {Low }}$ groups were $22.2 \%$ and $41.5 \%$, respectively $(p=0.017)$ (Figure 2$)$. Although there was a significant correlation $(\mathrm{r}=0.25$, $p=0.013$ ) between the ALBI scores and serum CA19-9 concentrations (Figure 3), the correlation coefficient was low. Therefore, we reasoned that the combination of the ALBI grade with the serum CA19-9 concentration might be more useful for predicting the prognosis of patients with PC compared with either indicator alone. For this purpose, we divided patients into groups: A: $\mathrm{ALBI}^{\mathrm{High}}$ and CA19-9 ${ }^{\mathrm{High}}$; B: $\mathrm{ALBI}^{\mathrm{High}}$ and CA19-9 ${ }^{\mathrm{Low}}$ or $\mathrm{ALBI}^{\mathrm{Low}}$ and CA19-9 ${ }^{\text {High, }}$; and $\mathrm{C}$ : $\mathrm{ALBI}^{\mathrm{Low}}$ and CA19-9 ${ }^{\mathrm{Low}}$. The 5-year OS rates of groups $\mathrm{A}, \mathrm{B}$, and $\mathrm{C}$ were $13.8 \%, 31.0 \%$, and $43.3 \%$, respectively ( $p=0.0006$ ) (Figure 4$)$.

Univariate analysis indicated that lymph node metastasis, lymphatic invasion, intrapancreatic nerve invasion, residual tumor, and the combination of the ALBI grade with the CA19-9 concentration were significantly associated with OS (Table II). We next included covariates with $p<0.1$ in univariate analysis in the multivariate analysis. Multivariate analysis indicated that the combination of ALBI grade with the CA19-9 concentration served as an independent prognostic indicator, along with lymph node metastasis, lymphatic invasion, and vascular invasion (Table II). 
Table I. Correlation between the albumin-bilirubin (ALBI) grade and patients' clinicopathological characteristics.

\begin{tabular}{|c|c|c|c|c|}
\hline Characteristic & Subgroup & $\operatorname{ALBI}^{\mathrm{High}}(\mathrm{n}=40), \mathrm{n}(\%)$ & ALBILow $(\mathrm{n}=60), \mathrm{n}(\%)$ & $p$-Value \\
\hline \multirow[t]{2}{*}{ Age } & $<70$ Years & $16(40.0 \%)$ & $24(40.0 \%)$ & $>0.99$ \\
\hline & $\geq 70$ Years & $24(60.0 \%)$ & $36(60.0 \%)$ & \\
\hline \multirow[t]{2}{*}{ Gender } & Male & $29(72.5 \%)$ & $32(53.3 \%)$ & 0.054 \\
\hline & Female & $11(27.5 \%)$ & $28(46.7 \%)$ & \\
\hline \multirow[t]{2}{*}{ Tumor size } & Small $(<3 \mathrm{~cm})$ & $21(53.8 \%)$ & $33(55.0 \%)$ & 0.466 \\
\hline & Large $(\geq 3 \mathrm{~cm})$ & $18(46.2 \%)$ & $27(45.0 \%)$ & \\
\hline \multirow[t]{3}{*}{ Tumor location } & Head & $29(72.5 \%)$ & $36(60.0 \%)$ & 0.430 \\
\hline & Body & $5(12.5 \%)$ & $10(16.7 \%)$ & \\
\hline & Tail & $6(15.0 \%)$ & $14(23.3 \%)$ & \\
\hline \multirow[t]{2}{*}{ T Category ${ }^{\mathrm{a}}$} & $\mathrm{T} 1 / \mathrm{T} 2$ & $1(2.5 \%)$ & $6(10.0 \%)$ & 0.150 \\
\hline & $\mathrm{T} 3$ & $39(97.5 \%)$ & $54(90.0 \%)$ & \\
\hline \multirow[t]{2}{*}{ Lymph node metastasis } & Absent & $16(40.0 \%)$ & $26(43.3 \%)$ & 0.741 \\
\hline & Present & $24(60.0 \%)$ & $34(56.7 \%)$ & \\
\hline \multirow[t]{2}{*}{ Lymphatic invasion } & ly $0 / 1$ & $20(51.3 \%)$ & $29(48.3 \%)$ & 0.774 \\
\hline & ly $2 / 3$ & $19(48.7 \%)$ & $31(51.7 \%)$ & \\
\hline \multirow[t]{2}{*}{ Vascular invasion } & v $0 / 1$ & $17(42.5 \%)$ & $31(51.7 \%)$ & 0.369 \\
\hline & $\mathrm{v} 2 / 3$ & $23(57.5 \%)$ & $29(48.3 \%)$ & \\
\hline \multirow[t]{2}{*}{ Intrapancreatic nerve invasion } & ne $0 / 1$ & $7(17.5 \%)$ & $17(28.3 \%)$ & 0.214 \\
\hline & ne $2 / 3$ & $33(82.5 \%)$ & $43(71.7 \%)$ & \\
\hline \multirow[t]{2}{*}{ Distant metastasis } & Absent & $39(97.5 \%)$ & $58(96.7 \%)$ & 0.811 \\
\hline & Present & $1(2.5 \%)$ & $2(3.3 \%)$ & \\
\hline \multirow[t]{3}{*}{ Surgical procedure } & PD & $29(72.5 \%)$ & $38(63.3 \%)$ & 0.295 \\
\hline & DP & $9(22.5 \%)$ & $21(35.0 \%)$ & \\
\hline & $\mathrm{TP}$ & $2(5.0 \%)$ & $1(1.7 \%)$ & \\
\hline \multirow[t]{2}{*}{ Residual tumor } & R0 & $34(85.0 \%)$ & $54(90.0 \%)$ & 0.451 \\
\hline & $\mathrm{R} 1$ & $6(15.0 \%)$ & $6(10.0 \%)$ & \\
\hline \multirow[t]{2}{*}{ Adjuvant chemotherapy } & Absent & $19(47.5 \%)$ & $24(40.0 \%)$ & 0.458 \\
\hline & Present & $21(52.5 \%)$ & $36(60.0 \%)$ & \\
\hline \multirow[t]{2}{*}{ Preoperative bile drainage } & Absent & $21(52.5 \%)$ & $47(78.3 \%)$ & 0.007 \\
\hline & Present & $19(47.5 \%)$ & $13(21.7 \%)$ & \\
\hline
\end{tabular}

PD: Pancreatoduodenectomy; DP: distal pancreatectomy; TP: total pancreatectomy; R0: no residual tumor; R1: microscopic residual tumor; ALBILow:

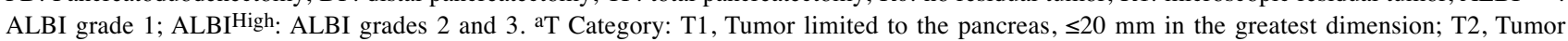
limited to the pancreas, $>20 \mathrm{~mm}$ in greatest dimension; T3, Tumor extends beyond the pancreas, but without involvement of the celiac artery or superior mesenteric artery.

\section{Discussion}

Here we showed that the ALBI grade was useful for predicting the prognosis of patients with PC. The ALBI score is calculated using only the serum albumin and bilirubin concentrations. A high ALBI score reflects decreased serum concentration of albumin. Serum albumin, which is the most abundant blood plasma protein, is produced in the liver and represents a major component plasma protein. Serum albumin is the standard factor used to assess a patient's nutritional status. Nutritional status affects the prognosis of patients with certain cancer. Therefore, there are close correlations among several nutritional assessment parameters that include serum albumin concentration, such as the prognostic nutritional index, Creactive protein (CRP) to albumin ratio, Glasgow Prognostic Score, and the prognosis of patients with PC (13-15).

Virchow first discovered the correlation between inflammation and malignant tumors in 1863 (16). The systemic inflammatory response induced by a cancer and its microenvironment play an important role in the development and progression of cancer (17). Pretreatment serum-based inflammatory indicators, such as the neutrophil to lymphocyte ratio, platelet to lymphocyte ratio, and CRP concentration, can be determined using routine tests and are linked to the prognosis of patients with PC $(18,19)$. Inflammation inhibits the synthesis of albumin (20), a decreased serum concentration of albumin is often present in patients with cancer. Therefore, the ALBI score reflects a patient's nutritional status and inflammatory status, which are both closely associated with the prognosis of patients with PC.

Furthermore, a high ALBI score reflects an increased serum concentration of bilirubin, which typically indicates liver dysfunction (21). Obstruction of the bile duct, which frequently occurs in patients with $\mathrm{PC}$, is also likely associated with increased serum bilirubin concentration. In contrast, serum albumin concentration decreases because of liver 


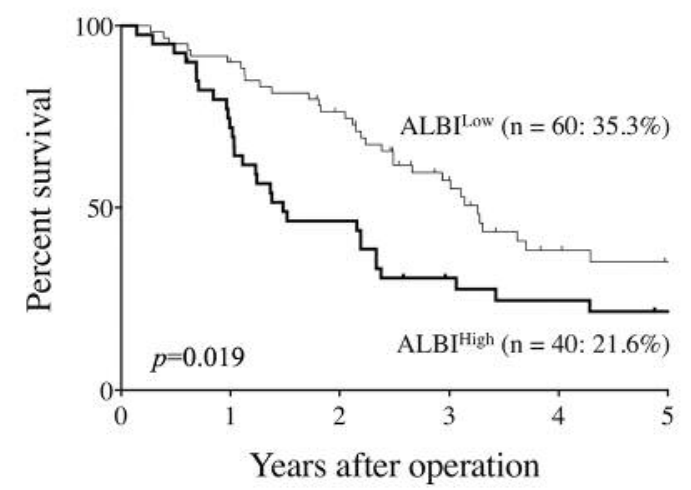

Figure 1. Overall survival curves according to the albumin-bilirubin (ALBI) grade. ALBI ${ }^{\text {Low }}$ : ALBI grade 1; ALBI ${ }^{\text {High }}$ : ALBI grades 2 and 3.

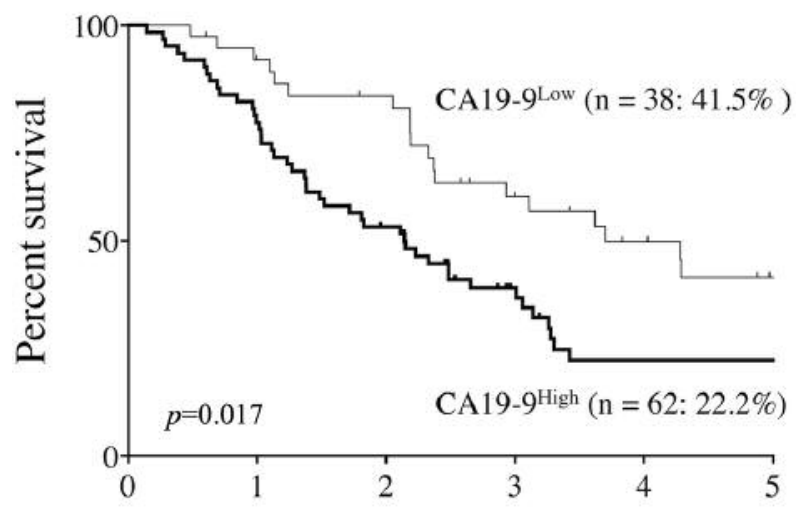

Figure 2. Overall survival curves according to the serum concentration of carbohydrate antigen 19-9 (CA19-9). CA19-9Low: $<35 \mathrm{U} / \mathrm{ml}$; CA199High: $\geq 35 \mathrm{U} / \mathrm{ml}$.

dysfunction. Moreover, impaired biliary excretion caused by obstruction of the bile duct by a tumor induces malabsorption, which adversely affects a patient's nutritional status.

We found that biliary drainage was performed significantly more frequently in patients of the ALBI ${ }^{\mathrm{High}}$ group than those of the ALBI ${ }^{\mathrm{Low}}$ group. Preoperative biliary drainage is a standard treatment for pancreatic head cancer with obstructive jaundice (22). Nevertheless, preoperative serum bilirubin concentration is significantly higher in patients with bile drainage than in those without bile drainage. Therefore, it is likely that the preoperative nutritional status of patients with high serum bilirubin concentration is poor, even after biliary drainage, which may be associated with poor prognosis of the patients studied here. In fact, we observed a significant negative correlation between serum albumin and bilirubin concentrations. Furthermore, bilirubin acts as an immunomodulator through the inhibition of T-cell activity (23). Overall, the ALBI score

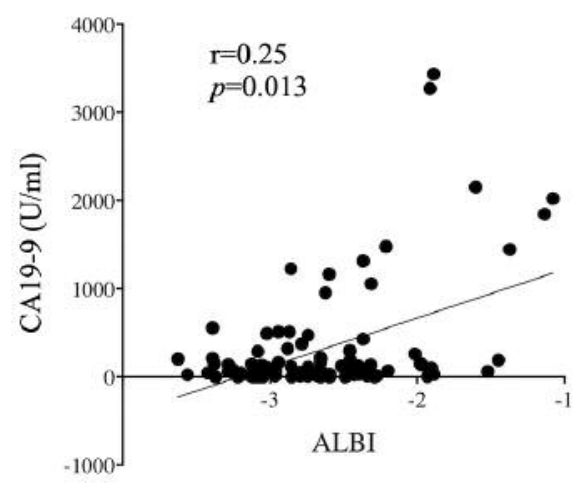

Figure 3. Correlations between the serum concentration of carbohydrate antigen 19-9 (CA19-9) and the albumin-bilirubin (ALBI) score.

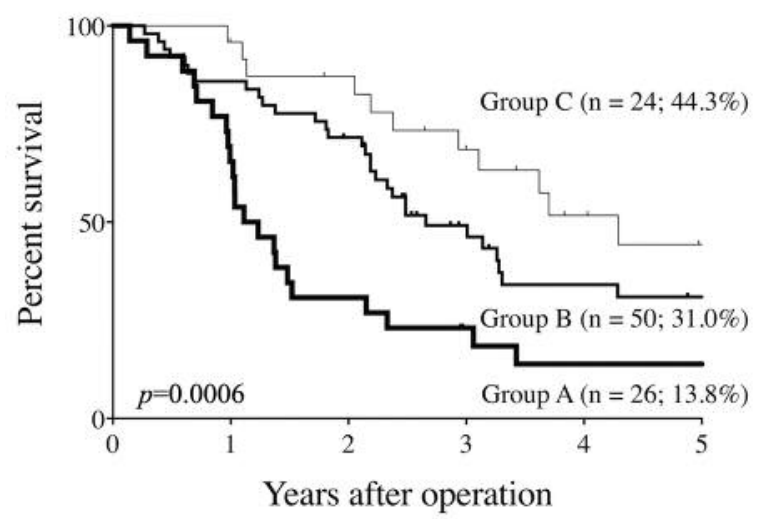

Figure 4. Overall survival curves according to group resulting from the combination of the albumin-bilirubin (ALBI) grade and serum concentration of carbohydrate antigen 19-9 (CA19-9). Group A: ALBI ${ }^{\text {High }}$ (ALBI grades 2 and 3) and CA19-9High ( $\geq 35 \mathrm{U} / \mathrm{ml}$ ); group B: $A L B I^{\text {High }}$ and CA19-9Low ( $<35 \mathrm{U} / \mathrm{ml}$ ) or ALBI Low (ALBI grade 1) and CA19-9High; and group C: ALBI ${ }^{\text {Low }}$ and CA19-9Low.

reflects patient-related factors, such as nutritional status, inflammation, and immune competence, which are associated with cancer progression and prognosis.

The ALBI score reflects patient-related factors, and the CA19-9 concentration, which is the most frequently used tumor marker for PC, is directly associated with cancer. These differences led us to speculate that combining the ALBI grade, based on the ALBI score, and serum CA19-9 level might be superior to using only the ALBI grade or serum CA19-9 level in predicting the prognosis of patients with PC. The data presented here convincingly support this hypothesis. Furthermore, multivariate analysis indicated that the combination of the CA19-9 concentration with the ALBI score served as an independent prognostic indicator of patients with PC. 
Table II. Univariate and multivariate analyses of clinicopathological factors of patients with pancreatic cancer.

\begin{tabular}{|c|c|c|c|c|c|c|c|}
\hline & & \multicolumn{3}{|c|}{ Univariate analysis } & \multicolumn{3}{|c|}{ Multivariate analysis } \\
\hline & & HR & $95 \% \mathrm{CI}$ & $p$-Value & HR & $95 \% \mathrm{CI}$ & $p$-Value \\
\hline Age & $\geq 70$ vs. $<70$ Years & 1.813 & $0.852-2.368$ & 0.18 & & & \\
\hline Gender & Female $v s$. male & 0.634 & $0.373-1.077$ & 0.092 & 0.557 & $0.328-1.013$ & 0.055 \\
\hline Preoperative bile drainage & Present $v s$. absent & 1.387 & $0.832-2.314$ & 0.21 & & & \\
\hline Operative procedure & DP/TP vs. PD & 1.129 & $0.677-1.884$ & 0.64 & & & \\
\hline Tumor size & $>3 v s .<3 \mathrm{~cm}$ & 1.440 & $0.877-2.364$ & 0.15 & & & \\
\hline T Category ${ }^{a}$ & $\mathrm{~T} 3$ vs. T1/2 & 1.337 & $0.485-3.676$ & 0.57 & & & \\
\hline Lymph node metastasis & Present $v s$. absent & 3.317 & $1.921-5.725$ & $<0.0001$ & 2.541 & $1.423-4.537$ & 0.0016 \\
\hline Lymphatic invasion & $1 \mathrm{y} 2 / 3$ vs. $1 \mathrm{y} 0 / 1$ & 2.667 & $1.597-4.464$ & 0.0002 & 2.309 & $1.245-4.274$ & 0.0079 \\
\hline Vascular invasion & $\mathrm{v} 2 / 3$ vs. $\mathrm{v} 0 / 1$ & 1.563 & $0.9524-3.516$ & 0.077 & 1.692 & $1.001-2.857$ & 0.049 \\
\hline Intrapancreatic nerve invasion & ne $2 / 3$ vs. ne $0 / 1$ & 2.688 & $1.364-5.291$ & 0.0043 & 1.629 & $0.781-3.401$ & 0.19 \\
\hline Distant metastasis & Present $v s$. absent & 2.479 & $0.764-8.045$ & 0.13 & & & \\
\hline Residual tumor & $\mathrm{R} 1$ vs. R0 & 1.116 & $1.131-4.983$ & 0.021 & 1.431 & $0.703-2.907$ & 0.3 \\
\hline Adjuvant chemotherapy & Present $v s$. absent & 0.896 & $0.546-1.468$ & 0.47 & & & \\
\hline Preoperative chemotherapy & Present $v s$. absent & 0.727 & $0.346-1.529$ & 0.4 & & & \\
\hline Combination of ALBI and CA19-9 & & & & 0.0011 & & & 0.0005 \\
\hline \multirow[t]{2}{*}{ Group } & A vs. C & 3.408 & $1.674-6.937$ & 0.0007 & 3.052 & $1.460-6.378$ & 0.003 \\
\hline & $\mathrm{B} v s . \mathrm{C}$ & 1.513 & $0.773-2.961$ & 0.23 & 0.956 & $0.473-1.931$ & 0.90 \\
\hline
\end{tabular}

CI: Confidence interval; HR: hazard ratio; PD: Pancreatoduodenectomy; DP: distal pancreatectomy; TP: total pancreatectomy; R0: no residual tumor; R1: microscopic residual tumor; CA19-9: carbohydrate antigen 19-9; ALBI: albumin-bilirubin grade. ${ }^{\text {aT }}$ Category: T1: Tumor limited to the pancreas: $\leq 20 \mathrm{~mm}$ in the greatest dimension; T2: Tumor limited to the pancreas: $>20 \mathrm{~mm}$ in greatest dimension; T3: Tumor extends beyond the pancreas: but without involvement of the celiac artery or superior mesenteric artery. Group A: ALBIHigh (ALBI grades 2 and 3) and CA19-9High $\left(\geq 35 \mathrm{U} / \mathrm{ml}\right.$ ); group B: ALBI ${ }^{\mathrm{High}}$ and CA19-9 ${ }^{\text {Low }}(<35 \mathrm{U} / \mathrm{ml})$ or ALBI ${ }^{\mathrm{Low}}$ (ALBI grade 1) and CA19-9High; and group C: ALBI ${ }^{\text {Low }}$ and CA19-9Low.

Our study has certain limitations. Firstly, its retrospective nature may have introduced bias. Secondly, the cut-off value of the ALBI score used to calculate the ALBI grade was determined by studies of HCC (8). Therefore, an optimal cutoff of the ALBI score for calculating the ALBI grade remains to be determined for patients with PC. In fact, the present study included only three patients with ALBI grade 3. Thirdly, the number of patients included in this study was small, and the results must be confirmed by a large-scale, prospective, randomized, controlled trial.

In conclusion, our study suggests the potential of the combination of the ALBI grade and the CA19-9 concentration for predicting the prognosis of patients with PC. Serum markers can be easily and noninvasively measured, which enhances the utility of this combination as a useful clinical marker to assess the prognosis of patients with PC.

\section{Conflicts of Interest}

The Authors declare that they have no conflict of interest in regard to this study.

\section{Authors' Contributions}

Study conception and design: Saito; Acquisition of data: Yagyu, Sakamoto, Uchinaka, Morimoto, Amisaki, Watanabe, Tokuyasu, Honjo, and Ashida; Analysis and interpretation of data: Yagyu and
Saito; Drafting of manuscript: Yagyu and Saito; Critical revision: Fujiwara; Final approval of the article: all Authors.

\section{Acknowledgements}

The Author thank Edanz Group (www.edanzediting.com/ac) for editing a draft of this article.

\section{Compliance with Ethical Standards}

Ethical approval: All procedures performed in studies involving human participants were in accordance with the ethical standards of the Institutional Research Committee and with the 1964 Helsinki Declaration and its later amendments or with comparable ethical standards.

\section{References}

1 Ueno H, Kosuge T, Matsuyama Y, Yamamoto J, Nakao A, Egawa S, Doi R, Monden M, Hatori T, Tanaka M, Shimada M and Kanemitsu K: A randomised phase III trial comparing gemcitabine with surgery-only in patients with resected pancreatic cancer: Japanese Study Group of Adjuvant Therapy for Pancreatic Cancer. Br J Cancer 101: 908-915, 2009. PMID: 19690548. DOI: $10.1038 /$ sj.bjc.6605256

2 Neoptolemos JP, Stocken DD, Bassi C, Ghaneh P, Cunningham D, Goldstein D, Padbury R, Moore MJ, Gallinger S, Mariette C, Wente MN, Izbicki JR, Friess H, Lerch MM, Dervenis C, Olah A, Butturini G, Doi R, Lind PA, Smith D, Valle JW, Palmer DH, 
Buckels JA, Thompson J, McKay CJ, Rawcliffe CL and Buchler MW: Adjuvant chemotherapy with fluorouracil plus folinic acid $v s$. gemcitabine following pancreatic cancer resection: A randomized controlled trial. JAMA 304: 1073-1081, 2010. PMID: 20823433. DOI: 10.1001/jama.2010.1275

3 Oettle H, Neuhaus P, Hochhaus A, Hartmann JT, Gellert K, Ridwelski K, Niedergethmann M, Zulke C, Fahlke J, Arning MB, Sinn M, Hinke A and Riess H: Adjuvant chemotherapy with gemcitabine and long-term outcomes among patients with resected pancreatic cancer: the CONKO-001 randomized trial. JAMA 310: 1473-1481, 2013. PMID: 24104372. DOI: 10.1001/ jama.2013.279201

4 Uesaka K, Boku N, Fukutomi A, Okamura Y, Konishi M, Matsumoto I, Kaneoka Y, Shimizu Y, Nakamori S, Sakamoto H, Morinaga S, Kainuma O, Imai K, Sata N, Hishinuma S, Ojima H, Yamaguchi R, Hirano S, Sudo T and Ohashi Y: Adjuvant chemotherapy of S-1 versus gemcitabine for resected pancreatic cancer: a phase 3, open-label, randomised, non-inferiority trial (JASPAC 01). Lancet 388: 248-257, 2016. PMID: 27265347. DOI: $10.1016 / \mathrm{s} 0140-6736(16) 30583-9$

5 Scara S, Bottoni P and Scatena R: CA 19-9: Biochemical and clinical aspects. Adv Exp Med Biol 867: 247-260, 2015. PMID: 26530370. DOI: 10.1007/978-94-017-7215-0_15

6 Nishida K, Kaneko T, Yoneda M, Nakagawa S, Ishikawa T, Yamane E, Nishioka B, Miyamoto Y, Takano H, Yoshikawa T and Kondo M: Doubling time of serum CA 19-9 in the clinical course of patients with pancreatic cancer and its significant association with prognosis. J Surg Oncol 71: 140-146, 1999. PMID: 10404129.

7 Haglund C, Roberts PJ, Kuusela P, Scheinin TM, Makela O and Jalanko H: Evaluation of CA 19-9 as a serum tumour marker in pancreatic cancer. British journal of cancer 53: 197-202, 1986. PMID: 3456787.

8 Johnson PJ, Berhane S, Kagebayashi C, Satomura S, Teng M, Reeves HL, O’Beirne J, Fox R, Skowronska A, Palmer D, Yeo W, Mo F, Lai P, Inarrairaegui M, Chan SL, Sangro B, Miksad R, Tada T, Kumada T and Toyoda H: Assessment of liver function in patients with hepatocellular carcinoma: a new evidence-based approach-the ALBI grade. J Clin Oncol 33: 550-558, 2015. PMID: 25512453. DOI: 10.1200/jco.2014.57.9151

9 Chen RC, Cai YJ, Wu JM, Wang XD, Song M, Wang YQ, Zheng $\mathrm{MH}$, Chen YP, Lin Z and Shi KQ: Usefulness of albuminbilirubin grade for evaluation of long-term prognosis for hepatitis B-related cirrhosis. J Viral Hepatitis 24: 238-245, 2017. PMID: 27862671. DOI: $10.1111 /$ jvh.12638

10 Kanda M, Tanaka C, Kobayashi D, Uda H, Inaoka K, Tanaka Y, Hayashi M, Iwata N, Yamada S, Fujii T, Sugimoto H, Murotani K, Fujiwara M and Kodera Y: Preoperative albumin-bilirubin grade predicts recurrences after radical gastrectomy in patients with pT2-4 gastric cancer. World J Surg 42: 773-781, 2018. PMID: 28920160. DOI: 10.1007/s00268-017-4234-x

11 Japan Pancreas Society: General Rules for the Study of Pancreatic Cancer. 7th ed. Kanehara, Tokyo, 2016.

12 Chan AW, Chan RC, Wong GL, Wong VW, Choi PC, Chan HL and To KF: New simple prognostic score for primary biliary cirrhosis: Albumin-bilirubin score. J Gastroenterol Hepatol 30: 1391-1396, 2015. PMID: 25753927. DOI: 10.1111/jgh.12938
13 Geng Y, Qi Q, Sun M, Chen H, Wang P and Chen Z: Prognostic nutritional index predicts survival and correlates with systemic inflammatory response in advanced pancreatic cancer. Eur J Surg Oncol 41: 1508-1514, 2015. PMID: 26343824. DOI: 10.1016/ j.ejso.2015.07.022

14 Morinaga S, Murakawa M, Katayama Y, Yamaoku K, Aoyama T, Kanazawa A, Higuchi A, Shiozawa M, Kobayashi S, Ueno M and Morimoto M: Glasgow prognostic score predicts clinical outcomes in patients with pancreatic cancer undergoing adjuvant gemcitabine monotherapy after curative surgery. Anticancer Res 35: 4865-4870, 2015. PMID: 26254380.

15 Haruki K, Shiba H, Shirai Y, Horiuchi T, Iwase R, Fujiwara Y, Furukawa $\mathrm{K}$, Misawa $\mathrm{T}$ and Yanaga $\mathrm{K}$ : The $\mathrm{C}$-reactive protein to albumin ratio predicts long-term outcomes in patients with pancreatic cancer after pancreatic resection. World J Surg 40: 2254-2260, 2016. PMID: 26956901. DOI: 10.1007/s00268-0163491-4

16 Coussens LM and Werb Z: Inflammation and cancer. Nature 420: 860-867, 2002. PMID: 12490959. DOI: 10.1038/nature01322

17 Grivennikov SI, Greten FR and Karin M: Immunity, inflammation and cancer. Cell 140: 883-899, 2010. PMID: 20303878. DOI: $10.1016 /$ j.cell.2010.01.025

18 Inoue D, Ozaka M, Matsuyama M, Yamada I, Takano K, Saiura A and Ishii H: Prognostic value of neutrophil-lymphocyte ratio and level of C-reactive protein in a large cohort of pancreatic cancer patients: A retrospective study in a single institute in Japan. Jpn J Clin Oncol 45: 61-66, 2015. PMID: 25341546. DOI: $10.1093 /$ jjco/hyu 159

19 Yu J, Ding Z, Yang Y and Liu S: Increased platelet-to-lymphocytes ratio is associated with poor long-term prognosis in patients with pancreatic cancer after surgery. Medicine 97: e11002, 2018. PMID: 29923983. DOI: 10.1097/md.000000000 0011002

20 Kaysen GA, Dubin JA, Muller HG, Rosales L, Levin NW and Mitch WE: Inflammation and reduced albumin synthesis associated with stable decline in serum albumin in hemodialysis patients. Kidney Int 65: 1408-1415, 2004. PMID: 15086482. DOI: $10.1111 /$ j.1523-1755.2004.00520.x

21 Tanriverdi O: A discussion of serum albumin level in advancedstage hepatocellular carcinoma: a medical oncologist's perspective. Med OncoI 31: 282, 2014. PMID: 25316265. DOI: 10.1007/s12032-014-0282-3

22 Kamisawa T, Wood LD, Itoi T and Takaori K: Pancreatic cancer. Lancet 388: 73-85, 2016. PMID: 26830752. DOI: 10.1016/ s0140-6736(16)00141-0

23 Liu Y, Li P, Lu J, Xiong W, Oger J, Tetzlaff W and Cynader M: Bilirubin possesses powerful immunomodulatory activity and suppresses experimental autoimmune encephalomyelitis. J Immunol 181: 1887-1897, 2008. PMID: 18641326.
Received January 29, 2019

Revised February 16, 2019

Accepted February 21, 2019 